031

\title{
USO DI UN AGAR SCREEN PER L'IDENTIFICAZIONE DI MRSA
}

Del Gaudio T., Porzio M., Tarricone N., 'Mosca A., 'Miragliotta G.

Laboratorio Analisi P.O. Andria ASL BA/I

Sezione di Microbiologia, Dipartimento MIDIM, Università di Bari

L'isolamento di ceppi di Staphylococcus aureus meticillinoresistenti (MRSA), è sempre più frequente, soprattutto in ambiente ospedaliero. MRSA sono spesso causa di fallimento terapeutico, anche per la loro coesistente resistenza ad un'ampia classe di antibiotici. Al fine di identificare precocemente i ceppi MRSA, presso il nostro Laboratorio viene utilizzato, in associazione ai comuni terreni di coltura, il terreno Oxacillin Resistance Screening Agar (Oxoid) contenente, tra gli altri componenti, oxacillina $(2 \mathrm{mg} / \mathrm{L})$ e quindi in grado di inibire i ceppi $S$. aureus meticillino-sensibili. $\mathrm{Su}$ questo terreno i ceppi MRSA vengono facilmente evidenziati grazie al blu di anilina che colora le colonie fermentanti il mannitolo. Dal gennaio 2003 sono stati isolati 179 S. aureus, dei quali 46 (25,6\%) MRSA. I ceppi MRSA hanno costituito: $62,5 \%$ del totale di $S$. aureus isolati da pazienti ricoverati in Rianimazione, $56,2 \%$ da pazienti ricoverati in reparti chirurgici, $14,6 \%$ da pazienti ricoverati in reparti dell'area medica e $7,3 \%$ da pazienti ambulatoriali. Le resistenze agli antimicrobici riscontrate per questi ceppi, sono illustrate 
nelle seguente tabella:

\begin{tabular}{cc}
\hline Antimicrobico & \% resistenza \\
\hline Ampicillina /Sub & 100 \\
\hline Cefalotina & 100 \\
\hline Ciprofloxacina & 93,5 \\
\hline Clindamicina & 89,1 \\
\hline Eritromicina & 95,6 \\
\hline Fosfomicina & 60,9 \\
\hline Ac. Fusidico & 4,3 \\
\hline Gentamicina & 93,5 \\
\hline Nitrofurantoina & 0 \\
\hline Norfloxacina & 95,6 \\
\hline Rifampicina & 6,5 \\
\hline Teicoplanina & 0 \\
\hline Tetraciclina & 8,7 \\
\hline Trim/Sul & 0 \\
\hline Vancomicina & 0
\end{tabular}

Abbiamo trovato una perfetta concordanza tra $\mathrm{i}$ risultati mostrati dall' Oxacillin Resistance Screening Agar e la resistenza alla oxacillina con il metodo in uso presso il nostro laboratorio (VITEK 32 Bio-Merieux). L'uso di questo terreno, permettendo un precoce riconoscimento dei ceppi MRSA, può a nostro avviso fornire al clinico un valido ausilio per un tempestivo ed adeguato trattamento terapeutico. 